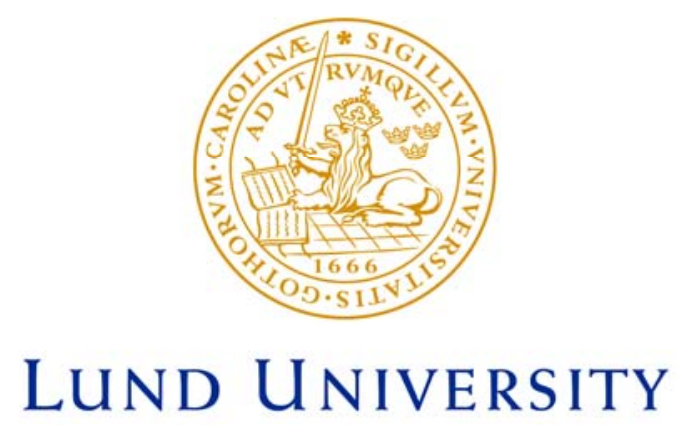

Faculty of Medicine

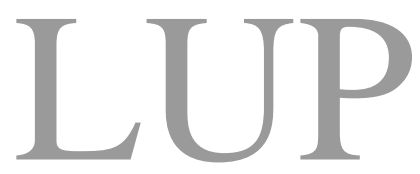

Lund University Publications Institutional Repository of Lund University

This is an author produced version of a paper published in International archives of occupational and environmental health. This paper has been peerreviewed but does not include the final publisher proofcorrections or journal pagination.

Citation for the published paper:

Jönsson LS, Broberg K, Axmon A, Bergendorf $U$, Littorin $M$, Jönsson BA.

"Levels of 1-hydroxypyrene, symptoms and immunologic markers in vulcanization workers in the southern Sweden rubber industries" International archives of occupational and environmental health, 2008, Issue: Apr 19.

http://dx.doi.org/10.1007/s00420-008-0310-8

Access to the published version may require journal subscription.

Published with permission from: Springer-Verlag 


\section{Levels of 1-hydroxypyrene, symptoms and immunologic markers in vulcanization workers in the southern Sweden rubber industries}

Lena S. Jönsson $(\bowtie)$, Karin Broberg, Anna Axmon, Ulf Bergendorf, Margareta Littorin, Bo A.G. Jönsson

Division of Occupational and Environmental Medicine, Department of Laboratory Medicine, Lund University Hospital, SE-221 85 Lund, Sweden

Corresponding to: Lena S. Jönsson, Division of Occupational and Environmental Medicine, University Hospital, 22185 Lund, Sweden

Phone no. +46 46 173192, Fax no. +46 46 143702, E-mail: lena_s.jonsson@med.lu.se 


\begin{abstract}
Objectives The aim of this study was to determine urinary 1-hydroxypyrene (1-HP) levels in contemporary Swedish vulcanization workers and in controls. These levels were used as an index substance for vulcanization fumes, as well as a biomarker for polycyclic aromatic hydrocarbons (PAHs). The risk of symptoms and changed levels of immunologic markers were investigated in relation to the 1-HP levels.

Methods Included in the study were 163 exposed workers and 106 controls. Medical and occupational histories were obtained by structured interviews. Symptoms were recorded and immunologic markers analysed in blood by routine analysis methods. Levels of 1-HP were determined by liquid chromatography and fluorescence detection.

Results The highest levels of 1-HP were found among exposed workers using injection and compression vulcanization, and lower levels were found among exposed workers vulcanizing with salt bath, hot air, microwaves or fluid-bed. Compared to controls, exposed workers had increased risks of eye symptoms, nosebleeds, burning and dry throat, hoarseness, severe dry cough, nausea and headache. Furthermore, exposed workers had elevated levels of neutrophils and total IgG (immunoglobulin subclass G). However, only for severe dry cough an evident exposure-response relationship with urinary 1-HP levels was found.

Conclusions This work clearly shows increased levels of urinary 1-HP in Swedish vulcanization workers. Furthermore, it demonstrates an increased risk of several symptoms and elevated levels of some immunologic markers in these workers. However, no obvious exposure-response relationships were found.
\end{abstract}

Keywords Airway symptoms, Biomarkers, Exposure-response relationships, PAH, Vulcanization fumes 


\section{Introduction}

The exposure situation in the rubber industry is very complex. A large diversity of compounds are used and additional compounds are formed in the different processes. Therefore, it is not possible to conduct an exposure assessment for every single compound. One way to handle the assessment of the multitudinous exposure is to use index substances, i.e. a specific substance as a marker of a larger group of compounds. In an earlier study by our group, urinary levels of 2-thiothiazolidine-4-carboxylic acid (TTCA) were used as an index substance for the exposure in the rubber industry. TTCA is a marker for carbon disulfide as well as for vulcanization fumes in general (Jönsson et al. 2007a). Some exposure-response relationships with symptoms (e.g. in the airways) and immunologic markers were found. However, it may be favourable to use more than one biomarker for more accurate risk assessments.

Workers in the rubber industry are at risk of exposure to polycyclic aromatic hydrocarbons (PAHs). Large amount of PAHs may be added to the rubber through extender oils, which may make up as much as $20 \%$ of the total weight of a tire or other rubber products (Talaska et al. 2002). In addition, PAHs may be present in the rubber fumes due to incomplete combustion or pyrolysis of organic material. Thus, exposure to PAHs may be a suitable index for vulcanization fumes in the rubber industry.

PAH is a generic name for several hundred different compounds. One of these is pyrene, which is metabolized into 1-hydroxypyrene (1-HP), which in turn is conjugated to a major part with glucuronide or sulfate, and excreted in urine (Singh et al. 1995). Urinary 1-HP is suggested to be the most relevant parameter for estimating individual exposure to PAHs (Dor et al. 1999).

This study aimed to monitor the 1-HP levels, as a measure of vulcanization fumes as well as PAHs, among subjects currently working in the Swedish rubber industry. Eight 
different companies in southern Sweden were examined and the 1-HP levels among employees working with different vulcanization processes at these companies were analysed. In addition, 1-HP levels in controls, not occupationally exposed to PAHs, were analysed.

Another aim of this study was to analyse exposure-response relationships between on the one hand vulcanization fumes/PAH exposure in the rubber industry and several symptoms and effects on the levels of different immunologic markers, on the other.

\section{Materials and methods}

Study subjects

Included in the study were 163 exposed workers who vulcanized with sulfur or worked in the same hall as people vulcanizing with sulfur, the same day as the urine samples were collected. They were employed at eight different rubber companies, which are described in detail elsewhere (Jönsson et al. 2007a). The exposed workers did not use personal protection devices. In addition, 106 controls with no occupational contact with rubber or plastic chemicals were included in the study. This cohort is described in detail in Jönsson et al. (2008). All study subjects were working in southern Sweden and present at work at the time of the medical examinations. Some individual characteristics of the exposed workers and the controls are shown in Table 1. The risk of symptoms and effects on levels of immunologic markers among all the exposed workers were compared to the controls in an earlier study (Jönsson et al. 2007b). Thus, these results are not presented here.

Complete information on urinary levels of 1-HP, symptoms and levels of immunologic markers were available for 154 exposed workers and 94 controls. For the remaining study subjects data on one or more parameters was missing, but these study subjects were included in the analyses when possible. The study subjects gave their informed written consent to take 
part in the study and the study was approved by the Regional Ethical Committee of Lund University.

\section{Medical examination}

Medical and occupational histories were obtained as described in Jönsson et al. (2007b). Questions dealt with symptoms, which had occurred during the past 12 months. The questions were the same as in Jönsson et al. (2007b). At the time of the medical examinations, the results of the biomarker analyses were not known to the workers or the investigators.

1-hydroxypyrene analysis

Urine was collected at one occasion from both exposed workers and controls during the last 4 h of an 8 h work shift. The samples were collected on Tuesdays, Wednesdays or Thursdays. The level of 1-HP was analysed as previously described (Jongeneelen and Anizon 1991). The limit of detection (LOD) was determined to be $0.01 \mathrm{ng} / \mathrm{ml}$ urine. Samples $<$ LOD were assigned a value of half the LOD. The precision was $7 \%$ at $2.3 \mathrm{ng} / \mathrm{ml}$. The results were within the tolerance limits in the Round Robin inter-comparison program (professor Dr. med. Hans Drexler, institute and out-patient clinic for occupational, social and environmental medicine, University of Erlangen-Nuremberg). The levels of 1-HP were adjusted for creatinine content, which was analysed enzymatically according to Mazzachi et al. (2000).

\section{Blood analysis}

Venous blood samples were collected during work, handled according to the instructions from the laboratories involved, and analysed by routine clinical methods as blinded samples. The same immunologic markers as in Jönsson et al. (2007b) were analysed. Atopy was defined as positive when at least one of the allergens in the Phadiatop test gave a positive response. 
Statistical analysis

Differences in 1-HP levels between exposed workers and controls, as well as between men and women, smokers and non-smokers, and snuffers and non-snuffers, in each exposure group, and between exposed workers vulcanizing with different methods, were estimated using analysis of variance (ANOVA). To examine the effect of vulcanization fumes/PAH exposure on the symptoms and immunologic markers mentioned above, all exposed workers were divided into three equally sized groups according to their urinary 1-HP levels (cut-off at 0.10 and $0.23 \mu \mathrm{mol} / \mathrm{mol}$ creatinine, respectively). Thereafter, each group was compared with the controls. To estimate the risk of the different symptoms, odds ratios (ORs) were estimated using logistic regression. Differences in immunologic markers were assessed by ANOVA, again using the trichotomized exposure measure.

A probability-probability plot suggested that the levels of 1-HP and immunologic markers should be transformed (natural logarithm) before use in the models. For the transformed variables, the formula $100\left(\mathrm{e}^{\beta}-1\right)$, where $\beta$ is the effect estimate, was used to estimate the percentage increase or decrease in the average level of the outcome in the evaluated group (Vittinghoff et al. 2005). Please note that all percentages presented were calculated using this formula.

Potential confounders (atopy, age, sex, smoking and snuffing habits) were evaluated for association with exposure and the dependent variables. Categorical factors were considered as confounders if the fraction between groups (e.g. men and women, smokers and non-smokers) differed more than $5 \%$ units, continuous factors if the median difference between groups exceeded $10 \%$. Associations between two continuous variables were determined using Spearman's coefficient of correlation $\left(\mathrm{R}_{\mathrm{S}}\right)$, where a coefficient greater than 0.15 was considered an association. Potential confounders were included in the model only if they were 
found to be associated with both the exposure and the dependent variable. If a factor was considered to be a confounder for at least one symptom, it was included in the models for all the symptoms. The procedure was same for immunologic markers.

Correlation between 2-thiothiazolidine-4-carboxylic acid (TTCA) and 1-HP was calculated using $\mathrm{R}_{\mathrm{S}}$.

For all statistical analyses, SPSS v.13.0 (SPSS Inc., Chicago, IL, USA) was used.

\section{Results}

The levels of 1-HP in urine from the exposed workers and controls are shown in Table 2. Adjusting for age and smoking habits, exposed workers were estimated to have in average 200\% higher urinary 1-HP level than the controls $(\mathrm{P}<0.001)$. The median of 1 -HP levels varied between 0.057 and $0.35 \mu \mathrm{mol} / \mathrm{mol}$ creatinine between companies. Furthermore, the levels of 1-HP differed between different subdivisions at the same company.

When workers vulcanizing with different methods were compared (Table 3), there were differences in 1-HP levels between workers vulcanizing with injection and compression compared to those vulcanizing with salt bath $(\mathrm{P}=0.004)$ and those vulcanizing with hot air, microwaves and fluid-bed $(\mathrm{P}=0.001)$. When comparing salt bath vulcanizing with hot air, microwaves and fluid-bed vulcanizing the difference was not statistically significant $(\mathrm{P}=$ 0.31). The analyses were adjusted for age, sex, atopy and smoking habits. When dividing the exposed workers into three equally sized groups according to urinary 1-HP levels, the number of workers vulcanizing with each method differed between the different exposure groups (Table 3). The pattern was opposite when compared to the same study subjects which were divided into three groups according to urinary TTCA levels (Jönsson et al. 2007b). Furthermore, there was no statistically significant correlation between the levels of 1-HP and TTCA in urine among these study subjects $\left(\mathrm{R}_{\mathrm{S}}=-0.11, \mathrm{P}=0.17\right)$. 
Adjusting for age, atopy, snuffing and smoking habits, there was no statistically significant difference $(\mathrm{P}=0.66)$ between exposed men and women regarding urinary 1-HP levels. The difference in average 1-HP level was only 9.2\%, women having higher 1-HP level than men. Neither, there was any statistically significant difference between the sexes within different vulcanization method strata (data not shown). However, among controls, there was a statistically significant difference $(\mathrm{P}<0.001)$ between sexes, women having in average 330\% higher 1-HP level than men.

Smokers had an increase in urinary 1-HP levels; exposed workers who smoked had in average 130\% higher 1-HP level than non-smokers ( $\mathrm{P}<0.001)$, while smoking controls had 140\% higher 1-HP level than non-smokers $(\mathrm{P}=0.002)$. Analyses were adjusted for sex and atopy. Snuffers also had an increase in urinary 1-HP levels, but it did not reach statistical significance (11\%, $\mathrm{P}=0.67$ among exposed workers and 60\%, $\mathrm{P}=0.19$ among controls). Analyses were adjusted for sex and smoking habits.

In at least one of the 1-HP subgroups, the exposed workers had increased risks of symptoms from the eyes (itching, running, and/or burning) and throat (burning and dryness), as well as hoarseness and severe dry cough, compared to the controls (Table 4). An increased risk of nosebleeds (but of no other nasal symptoms) and of nausea and headache was also observed. The risk of symptoms in the lower airway, such as dyspnea, etc. was slightly elevated in all subgroups. However, the increased risks of dyspnea, etc. were not statistically significant. Only for severe dry cough, there was an evident exposure-response relationship with urinary 1-HP levels.

An increased concentration of neutrophils was found among workers with high levels of 1-HP (Table 5). Furthermore, increased levels of total plasma IgG were observed in all 1-HP subgroups, with the highest concentration among exposed workers with low 1-HP levels. 
Furthermore, we observed increased levels of total IgE in all 1-HP subgroups, but it did not reach statistical significance. No clear exposure-response relationships were found.

Excluding of study subjects with presumable Eastern Asian descent was performed in the whole group in an earlier work (Jönsson et al. 2007b). The exclusion did not affect the significance levels of the effect estimates.

\section{Discussion}

This work demonstrates clearly increased levels of urinary 1-HP in contemporary Swedish vulcanization workers. Furthermore, it demonstrates an increased risk of symptoms from the eyes and airways, as well as for nosebleeds, nausea and headache in these workers. They were also shown to have elevated levels of total IgG. However, no obvious exposure-response relationships were found for these symptoms and immunologic markers using 1-HP as a biomarker of exposure.

Urinary levels of 1-HP of a rather high magnitude were found in the exposed workers compared to the controls. Company 2 (division B), 5 and 6 had particularly high levels of 1HP. These divisions had a large proportion of the production done in compression and injections units.

The diet is estimated as an important source of PAH intake in the non-occupationally exposed population (IARC 1983). In the present study the information on food intake was insufficient for inclusion in the models. However, this exposure may be of minor importance in this study as the differences between exposed workers and controls were rather large regarding 1-HP levels in urine.

Smoking is a known source for PAH exposure. Thus, reference values as a 95th percentile for smokers and non-smokers are 0.76 and $0.24 \mu \mathrm{mol} / \mathrm{mol}$ creatinine, respectively 
(Jongeneelen 2001). In our study an increase in 1-HP levels in smokers compared to nonsmokers were also found, but the difference appeared to be smaller here.

Earlier studies in the rubber industry have mainly included men. In this survey we included both sexes. However, we observed no differences between male and female rubber workers regarding 1-HP levels in urine. Notably, a statistically significant difference was observed between sexes among controls, women having more 1-HP than men. However, there is no straightforward explanation for this.

To our knowledge, only one earlier study has measured 1-HP in the rubber industry (Talaska et al. 2002). In that study the 1-HP geometric mean levels in $24 \mathrm{~h}$ urine samples were about two times the levels in our study. The 1-HP median among controls was in accordance with an earlier study in Sweden (Levin 1995).

The present work demonstrated an increased risk of several symptoms. Elevated levels of total IgG and neutrophils in the exposed workers were also observed. Only for severe dry cough an exposure-response relationship were found. Regarding the levels of neutrophils, the largest effect was seen in the highest 1-HP subgroup.

There may be an information bias concerning reporting of symptoms, both on the part of the observed workers and the observer. However, this seems to be of minor importance since there was a high to moderate agreement between interviews performed by a physician and self-administered questionnaires answered before the interviews (data not shown).

The urinary levels of 1-HP reflects the PAH exposure only during the last couple of days, due to the rather short half-life (18 h) of the metabolite (Buchet et al. 1992). On the other hand, the occurrence of symptoms was asked for during 12 months. The change in the levels of immunologic markers was also suspected to reflect a longer time of exposure. Furthermore, there may be a variation in the individual immune response over time. Thus, there might be a problem to observe exposure-response relationships in the present study. 
However, symptoms during the last 3 days were also recorded and when repeating the analyses using this data, the pattern was similar (data not shown).

In the present study, 1-HP was used as an index substance of vulcanization fumes as well as a biomarker of PAH exposure. There are several other studies indicating symptoms from the eyes and airways in the rubber industry (Weeks et al. 1981; Sparks et al. 1982; Zuskin et al. 1996; Fine and Peters 1976). However, the association between these symptoms and PAH exposure has not been studied in the rubber industry before.

In earlier studies where 1-HP has been measured, it has been applied as an index substance of PAHs (Dor et al. 1999). Major attention has been paid to malignant diseases (Boffetta et al. 1997). Nevertheless, some studies have examined nonmalignant diseases and immunological effects due to PAH exposures in other industries than the rubber industry (Mastrangelo et al. 2003; Randem et al. 2004; Burstyn et al. 2003). In these studies increased levels of IgE, increased risk of eye irritation, chest tightness and chest wheezing and mortality from chronic bronchitis, emphysema and asthma were found. In the present study, no clear association between symptoms/immunologic markers and urinary levels of 1-HP was observed.

There is a problem concerning the exposure to PAHs of large molecular type, as they often are associated with particles and it is not known that, which effects come from particles and which come from PAHs. In the present study, the correlation $\left(\mathrm{R}_{\mathrm{S}}\right)$ between personally sampled respirable particles in air and urinary 1-HP levels was 0.51 in 52 exposed workers with available data (CH Lindh, personal communication).

There is no threshold limit for 1-HP in the rubber industry. However, Jongeneelen (2001) has proposed a biological exposure index for coke works and the primary aluminum industry of 2.3 and $4.9 \mu \mathrm{mol} / \mathrm{mol}$ creatinine, respectively. Two indices are proposed since the proportion of pyrene, the compound that is metabolized to 1-HP, varies between the 
industries. Pyrene itself has low toxicity; the toxicity of PAH arises from other compounds, e.g. benzo(a)pyrene but the levels of the metabolites of benzo(a)pyrene are too low to be accurately monitored. The indices are not based on health effects but on what is considered to be technically manageable. A health based biological exposure limit would probably be about ten times lower (Netherlands Health Counsel 1994). Many of the subjects in our study would be above such a low biological exposure limit. When the Netherlands Health Counsel (1994) proposed this limit they based it on malignant outcomes. A biological exposure index based on the outcomes studied in this survey cannot be proposed due to the inconsistence we found in exposure-response relationships.

We have previously used TTCA as a biomarker of exposure and found some exposureresponse relationships with symptoms (e.g. in the airways) and immunologic markers, although there might be a healthy worker selection (Jönsson et al. 2007b). It was suggested that more biomarkers should be used together with TTCA. From this study, 1-HP did not seem to be valuable for this purpose. However, the lack of clear exposure-response relationships might be due to a healthy worker selection as the study population was the same as in the previous work (Jönsson et al. 2007b). Furthermore, due to rather high concentrations of 1-HP in the exposed workers, 1-HP is a valuable biomarker for determination of risk of malignant outcomes in rubber workers.

\section{Acknowledgements}

We thank Eva Assarsson, Inger Bensryd and Kerstin Diab for collecting the samples and Åsa Amilon for analysing 1-HP in a skilful way. The study was supported by AFA [Swedish Labour Market Insurance Company], the Swedish Council for Working Life and Social Research, the Swedish Research Council, Skane county council's research and development foundation, and the Medical Faculty at Lund University, Sweden 


\section{References}

Boffetta P, Jourenkova N, Gustavsson P (1997) Cancer risk from occupational and environmental exposure to polycyclic aromatic hydrocarbons. Cancer Causes Control 8:444-72

Buchet JP, Gennart JP, Mercado-Calderon F, Delavignette JP, Cupers L, Lauwerys R (1992) Evaluation of exposure to polycyclic aromatic hydrocarbons in a coke production and a graphite electrode manufacturing plant: Assessment of urinary excretion of 1hydroxypyrene as a biological indicator of exposure. Br J Ind Med 49:761-8

Burstyn I, Boffetta P, Heederik D, Partanen T, Kromhout H, Svane O et al (2003) Mortality from obstructive lung diseases and exposure to polycyclic aromatic hydrocarbons among asphalt workers. Am J Epidemiol 158:468-78

Dor F, Dab W, Empereur-Bissonnet P, Zmirou D (1999) Validity of biomarkers in environmental health studies: The case of PAHs and benzene. Crit Rev Toxicol 29:129-68

Fine LJ, Peters JM (1976) Respiratory morbidity in rubber workers: I. Prevalence of respiratory symptoms and disease in curing workers. Arch Environ Health 31:5-9

International Agency for Research on Cancer (IARC) (1983) Polynuclear aromatic compounds, Part 1: Chemicals, environmental and experimental data. Monographs on Evaluation of Carcinogenic Risk of Chemicals to Humans. Science Publ. No. 32. IARC, Lyon

Jongeneelen FJ, Anzion RBM (1991) 1-hydroxypyrene. In: Angerer J, Schaller KH, editors. Analysis of hazardous substances in biological materials. Vol. 3. Wiley-VCH, Weinheim

Jongeneelen FJ (2001) Benchmark guideline for urinary 1-hydroxypyrene as biomarker of occupational exposure to polycyclic aromatic hydrocarbons. Ann Occup Hyg 45:3-13 
Jönsson LS, Broberg K, Bergendorf U, Axmon A, Littorin M, Jönsson BAG (2007a) Levels of 2-thiothiazolidine-4-carboxylic acid (TTCA) and effect modification of polymorphisms of glutathione-related genes in vulcanization workers in the southern Sweden rubber industries. Int Arch Occup Environ Health 80:589-98

Jönsson LS, Broberg K, Axmon A, Jönsson BAG, Littorin M (2007b) Symptoms and immunologic markers among vulcanization workers in rubber industries in southern Sweden. Scand J Work Environ Health 33:272-9

Jönsson LS, Jönsson BAG, Axmon A, Littorin M, Broberg K (2008) Influence of glutathionerelated genes on symptoms and immunologic markers among vulcanization workers in the southern Sweden rubber industries. Int Arch Occup Environ Health, in press

Levin JO (1995) First international workshop on hydroxypyrene as a biomarker for PAH exposure in man--summary and conclusions. Sci Total Environ 163:164-8

Littorin M, Rylander L, Skarping G, Dalene M, Welinder H, Strömberg U et al (2000) Exposure biomarkers and risk from gluing and heating of polyurethane: a cross sectional study of respiratory symptoms. Occup Environ Med 57:396-405

Mastrangelo G, Clonfero E, Pavanello S, Fedeli U, Fadda E, Turato A et al (2003) Exposure to diesel exhaust enhances total IgE in non-atopic dockers. Int Arch Occup Environ Health 76:63-8

Mazzachi BC, Peake MJ, Ehrhardt V (2000) Reference range and method comparison studies for enzymatic and Jaffe creatinine assays in plasma and serum and early morning urine. Clin Lab 46:53-5

Netherlands Health Counsel (1994) Health based calculated occupational cancer risk values. Draft report. The Hague: DECOS-committee 
Nielsen J, Welinder H, Schütz A, Skerfving S (1988) Specific serum antibodies against phthalic anhydride in occupationally exposed subjects. J Allergy Clin Immunol 82:126-33

Peters S, Talaska G, Jönsson BAG, Kromhout H, Vermeulen R (2008) Polycyclic Aromatic Hydrocarbon Exposure, Urinary Mutagenicity and DNA Adducts in Rubber Manufacturing Workers. Cancer Epidemiol Biomarkers Prev (in press)

Randem BG, Ulvestad B, Burstyn I, Kongerud J (2004) Respiratory symptoms and airflow limitation in asphalt workers. Occup Environ Med 61:367-9

Singh R, Tucek M, Maxa K, Tenglerova J, Weyand EH (1995) A rapid and simple method for the analysis of 1-hydroxypyrene glucuronide: a potential biomarker for polycyclic aromatic hydrocarbon exposure. Carcinogenesis 16:2909-15

Sparks PJ, Smith TJ, Fine LJ, Treitman RD, Spiegelman DL (1982) Respiratory morbidity among processing and mill workers. A cross-sectional survey in three tiremanufacturing plants. J Occup Med 24:690-5

Talaska G, Maier A, Henn S, Booth-Jones A, Tsuneoka Y, Vermeulen R et al (2002) Carcinogen biomonitoring in human exposures and laboratory research: Validation and application to human occupational exposures. Toxicol Lett 134:39-49

Vittinghoff E, Shiboski SC, Glidden DV, McCulloch CE (2005) Regression methods in biostatistics. Linear, logistic, survival and repeated measures models: Springer, New York, p 126

Weeks JL, Peters JM, Monson RR (1981) Screening for occupational health hazards in the rubber industry. Part II: health hazards in the curing department. Am J Ind Med 2:14351

Zuskin E, Mustajbegovic J, Schachter EN, Doko-Jelinic J, Budak A (1996) Longitudinal study of respiratory findings in rubber workers. Am J Ind Med 30:171-9 
Table 1 The characteristics of the exposed workers and the controls

\begin{tabular}{|c|c|c|}
\hline & $\begin{array}{l}\text { Exposed workers } \\
\qquad(\mathrm{n}=163)\end{array}$ & $\begin{array}{l}\text { Controls } \\
(\mathrm{n}=106)\end{array}$ \\
\hline Age, median (range) years & $38(19-65)$ & $42(20-63)$ \\
\hline Sex (male/female) & 83 / 80 & $50 / 56$ \\
\hline Smoking, $\mathrm{n}(\%)^{\mathrm{a}}$ & $51(31)$ & 39 (37) \\
\hline Snuffing, $\mathrm{n}(\%)^{\mathrm{a}}$ & $30(18)$ & $21(20)$ \\
\hline Atopy, n (\%) & $50(32)$ & $29(28)$ \\
\hline Eastern Asian descent, n (\%) ${ }^{b}$ & 21 (13) & - \\
\hline
\end{tabular}

\footnotetext{
${ }^{\mathrm{a}}$ Denoted smoker or snuffer if stopped $<6$ months ago

${ }^{\mathrm{b}}$ Based on the names
} 
Table 2 Levels of 1-hydroxypyren (1-HP, $\mu \mathrm{mol} / \mathrm{mol}$ creatinine) in controls and exposed workers at different companies and different subdivision of the same company

\begin{tabular}{|c|c|c|c|c|}
\hline Company & $\mathrm{N}$ & Median & Geometric & Range \\
\hline
\end{tabular}

\begin{tabular}{|c|c|c|c|c|c|}
\hline Controls & 106 & 0.071 & 0.042 & $<\mathrm{LOD}-0.35$ & $<\mathrm{LOD}-0.23$ \\
\hline All exposed workers & 163 & 0.14 & 0.12 & $<\mathrm{LOD}-1.3$ & $0.023-0.44$ \\
\hline Company 1 & 10 & 0.16 & 0.15 & $0.085-0.23$ & $0.086-0.23$ \\
\hline Company 2 & 16 & 0.31 & 0.25 & $<\mathrm{LOD}-0.84$ & $0.076-0.64$ \\
\hline Division A & 5 & 0.18 & 0.22 & $<\mathrm{LOD}-0.49$ & $0.078-0.49$ \\
\hline Division B & 11 & 0.33 & 0.27 & $0.072-0.84$ & $0.079-0.78$ \\
\hline Company 3 & 36 & 0.14 & 0.12 & $0.003-1.3$ & $0.014-0.46$ \\
\hline Division A & 29 & 0.17 & 0.13 & $0.003-1.3$ & $0.010-0.51$ \\
\hline Division B & 3 & 0.13 & 0.095 & $0.050-0.13$ & $0.050-0.13$ \\
\hline Factory 2 & 4 & 0.087 & 0.072 & $0.015-0.41$ & $0.015-0.41$ \\
\hline Company 4 & 21 & 0.057 & 0.038 & $<\mathrm{LOD}-0.29$ & $<\mathrm{LOD}-0.22$ \\
\hline Company 5 & 15 & 0.28 & 0.18 & $<\mathrm{LOD}-0.61$ & $0.018-0.58$ \\
\hline Company 6 & 10 & 0.35 & 0.27 & $0.081-0.89$ & $0.082-0.88$ \\
\hline Company 7 & 11 & 0.065 & 0.074 & $0.015-0.36$ & $0.020-0.32$ \\
\hline Company 8 & 44 & 0.13 & 0.14 & $0.010-0.66$ & $0.037-0.41$ \\
\hline Factory 1 & 12 & 0.10 & 0.13 & $0.021-0.40$ & $0.031-0.39$ \\
\hline Factory 2 & 32 & 0.13 & 0.14 & $0.01-0.66$ & $0.034-0.42$ \\
\hline
\end{tabular}

LOD limits of detection 
Table 3 Levels of 1-hydroxypyrene (1-HP) and the distribution of exposure for different vulcanization methods in a group of 157 workers from the Swedish rubber industry

\begin{tabular}{|c|c|c|c|c|c|}
\hline \multirow[t]{3}{*}{ Vulcanization method } & \multicolumn{5}{|c|}{ Number (\%) of workers in each group } \\
\hline & 1-HP/mol creatinine & & & & Change (95\% CI) ${ }^{a}$ \\
\hline & ( $\mu$ mol )geometric mean (range) & Low 1-HP & Intermediate 1-HP & High 1-HP & \\
\hline Compression and injection & $0.16(<\mathrm{LOD}-1.3)$ & $24(26)$ & $31(33)$ & $39(41)$ & \\
\hline Hot air, microwaves, fluid-bed & $0.069(<\mathrm{LOD}-0.85)$ & $11(46)$ & $9(38)$ & $4(17)$ & $-60(-76--34)$ \\
\hline Salt bath & $0.087(<\mathrm{LOD}-0.51)$ & $17(44)$ & $12(31)$ & $10(26)$ & $-47(-65--18)$ \\
\hline
\end{tabular}

LOD limit of detection, $C I$ confidence interval

${ }^{a}$ Percentage change in the average urinary 1-HP levels among employees working with different continuous vulcanization (hot air, microwaves,

fluid-bed or salt bath) compared to employees using compression and injection vulcanization. Effect estimates were adjusted for age, sex, atopy and smoking habits

Cut-off was set at 0.10 and $0.23 \mu \mathrm{mol} / \mathrm{mol}$ creatinine, respectively. Three employees were not possible to classify and three employees working with steam vulcanization were not included. 
Table 4 Odds ratios (ORs) with 95\% confidence intervals (CIs) of symptoms during the past 12 months among exposed workers with different levels of 1-hydroxypyrene (cut-off at 0.10 and $0.23 \mu \mathrm{mol} / \mathrm{mol}$ creatinine, respectively), compared to controls ( $\mathrm{n}=106$ ).

\begin{tabular}{|c|c|c|c|}
\hline \multirow[t]{3}{*}{ Symptom } & \multicolumn{3}{|c|}{ 1-HP } \\
\hline & $\begin{array}{l}\text { Low } \\
(n=54)\end{array}$ & $\begin{array}{l}\text { Intermediate } \\
\qquad(\mathrm{n}=55)\end{array}$ & $\begin{array}{l}\text { High } \\
(n=54)\end{array}$ \\
\hline & OR $(95 \% \mathrm{CI})^{\mathrm{a}}$ & OR $(95 \% \mathrm{CI})^{\mathrm{a}}$ & OR $(95 \% \text { CI })^{a}$ \\
\hline Itching, running or burning eyes & $3.1(1.5-6.4)$ & $3.8(1.8-7.7)$ & $3.5(1.7-7.3)$ \\
\hline Running nose & $1.3(0.59-2.7)$ & $1.1(0.54-2.4)$ & $0.99(0.45-2.2)$ \\
\hline Nose stuffiness & $1.3(0.64-2.7)$ & $0.71(0.33-1.5)$ & $0.81(0.37-1.7)$ \\
\hline Sneezing and/or nose itching & $1.0(0.53-2.1)$ & $0.96(0.49-1.9)$ & $0.82(0.41-1.7)$ \\
\hline \multicolumn{4}{|l|}{ One or more of nasal } \\
\hline symptoms mentioned above & $1.5(0.77-3.0)$ & $1.6(0.82-3.3)$ & $1.2(0.59-2.4)$ \\
\hline Nosebleeds & $3.9(1.3-11)$ & $4.2(1.5-12)$ & $2.0(0.60-6.8)$ \\
\hline Throat burning and dryness & $4.4(2.0-9.6)$ & $3.9(1.8-8.4)$ & $1.4(0.62-3.4)$ \\
\hline Hoarseness & $2.8(1.1-7.1)$ & $2.3(0.93-5.9)$ & $1.8(0.68-4.8)$ \\
\hline
\end{tabular}

Dyspnea, wheezing and/or

chest tightness

$1.5(0.65-3.3) \quad 1.1(0.48-2.4) \quad 1.3(0.57-2.8)$

Severe dry cough

$3.3(1.3-8.3)$

$3.6(1.5-9.0)$

$6.9(2.9-17)$

Nausea

$3.7(1.1-13)$

$4.9(1.6-16)$

$4.4(1.4-14)$

Headache

$3.9(1.9-8.2)$

$2.8(1.3-5.7)$

$1.9(0.93-4.0)$

\footnotetext{
${ }^{\mathrm{a}}$ Effect estimates are adjusted for age, sex and smoking habits.
} 
Table 5 Percentage change in the average value of the immunologic markers in each examined group (exposed workers with different levels of 1-hydroxypyrene [cut-off at 0.10 and $0.23 \mu \mathrm{mol} / \mathrm{mol}$ creatinine, respectively]) compared to the controls ( $\mathrm{n}=103)$.

\begin{tabular}{ccc}
\hline Low & Intermediate & High \\
$(\mathrm{n}=53)$ & $(\mathrm{n}=52)$ & $(\mathrm{n}=54)$
\end{tabular}

Change (95\% CI) ${ }^{\mathrm{a}} \quad$ Change (95\% CI) ${ }^{\mathrm{a}} \quad$ Change (95\% CI) ${ }^{\mathrm{a}}$

$\begin{array}{lccc}\text { Leukocytes } & 3.6(-4.8-13) & -0.30(-8.3-8.4) & 8.5(-0.20-18) \\ \text { Neutrophils } & 4.7(-6.3-17) & -1.7(-12-9.7) & 12(0.30-25) \\ \text { Eosinophils } & -1.4(-18-18) & 16(-3.1-38) & 13(-5.0-35) \\ \alpha 1 \text {-antitrypsin } & -0.20(-5.3-5.1) & 0.70(-4.3-6.1) & 4.4(-0.90-10) \\ \text { C-reactive Protein } & -3.9(-14-7.0) & 4.7(-6.0-17) & 3.4(-7.2-15) \\ \text { IgG } & 14(6.1-22) & 11(3.8-19) & 8.9(1.5-17) \\ \text { IgA } & -5.7(-18-8.3) & 1.3(-12-16) & -8.6(-20-5.0) \\ \text { IgM } & 3.3(-10-19) & 13(-2.1-30) & 2.1(-11-18) \\ \text { IgE } & 45(-7.6-130) & 44(-8.1-120) & 13(-28-77)\end{array}$

CI confidence interval

${ }^{\text {a }}$ Adjusted for age, sex and smoking habits. 